\title{
Dança de Zumba como instrumento em prol da saúde e do bem estar para comunidades periféricas do Município
}

Jailson do Nascimento Alves ${ }^{1}$; Deise Cristiane do Nascimento ${ }^{2}$

\begin{abstract}
Resumo: O objetivo do trabalho é compreender os fatores motivacionais das aulas de Zumba em prol da saúde e do bem estar nas comunidades periféricas do município de Petrolina/PE, os quais são praticantes nas chamadas "Academia da cidade". A amostra é composta por pessoas adultas do gênero feminino e a pesquisa caracterizouse como descritiva, pois foi aplicado um questionário com questões fechadas sobre os objetivos traçados e as respostas foram tabeladas no programa Microsoft Office Word 2007. Os resultados obtidos demonstram o quanto os alunos melhoraram em seu condicionamento físico ocasionando um melhor bem estar entre os praticantes da dança em locais abertos e gratuitos para quaisquer idades. Os resultados demonstram ainda que para a população os motivos de adesão mais citados foram por ser uma aula relacionada à dança e sensação de bem estar pós aula, o que obriga a Gestão Pública a ocupar mais espaço com a prática da dança como exercício físico, provocando menos gasto no setor da saúde.
\end{abstract}

Palavras-Chave: Bem Estar; Dança; Saúde; Zumba.

\section{Zumba Dance as an instrument to promote health and welfare for communities of peripheral Municipality}

\begin{abstract}
Zumba classes for health and well-being in remote communities in the municipality of Petrolina/PE, which are practitioners in so-called "City Academy". The sample is composed of adult females and the research was characterized as descriptive, it was applied a questionnaire with closed questions about the goals set and the answers were tabulated in Microsoft Office Word 2007 program The results show how much students improved in their physical condition causing a better wellbeing among dance practitioners in open and free places to any ages. The results also show that for the population the most cited reason of accession were to be a class related to dance and sense of well being after class, which requires the Public Management to take up more space with the practice of dance as exercise, causing less spending in the health sector.
\end{abstract}

Keywords: Wellness. Dance. Health. Zumba.

\section{Introdução}

$\mathrm{Na}$ atualidade aumentou-se muito a perspectiva de vida do ser humano, consequentemente a preocupação com a saúde e a qualidade de vida vem aumentando também e assim as pessoas procuram com mais frequência formas diferenciadas de praticar exercício físico regularmente.

\footnotetext{
1 Pós-graduando em Gestão Pública Municipal da Universidade Federal do Vale do São Francisco - UNIVASF. E-mail: jailsonnascialves@hotmail.com;

${ }^{2}$ Professora orientadora de monografia do curso de Pós-graduação (Lato Sensu) em Gestão Pública Municipal da UNIVASF. É professor auxiliar da Faculdade de Ciências Aplicadas e Sociais de Petrolina. E-mail: deise.nascimento@facape.br.
} 
Com a influência da mídia divulgando que a atividade física é uma das soluções para muitos males da saúde que atingem a população, ocasiona na procura das pessoas por exercícios que venham a contribuir para a promoção e prevenção da saúde, porém, notando-se que algumas pessoas não persistem na atividade continuada e acabam desistindo em pouco tempo de prática. Um dos motivos que leva a desistência de alunos pode ser associado à falta de programas ou aulas que sejam agradáveis a todos os públicos. $\mathrm{Na}$ busca por programas que estimule as pessoas na prática do exercício físico e que exista uma continuidade, encontra a história do movimento da Zumba.

Este é o objetivo da empresa Zumba Fitness, LLC trazendo algo novo no mercado fitness, (BASIC STEPS LEVEL, 1, 2013), a qual propõe oferecer um diferencial quanto a motivação e adesão a prática de exercícios físicos através da Zumba. É com esta curiosidade que venho a pesquisar quais os motivos que levam as pessoas a aderirem esta modalidade. Em 2001, Alberto Perlman e Alberto Aghion associaramse a Beto Perez para a criação da empresa Zumba Fitness LCC. Seis anos após sua criação, o programa já contava com 10.000 instrutores, era disponibilizado em mais de 30 países e já havia vendido mais de três milhões de DVDs. (ARSEGO, 2012, p. 12).

Ferreira (1993) determina que a adesão ao exercício físico signifique o ato ou o efeito de aderir, ou tornar-se intimamente ligado. Já Barbanti (1994) entende que aderência é a participação mantida constante em programas de exercícios, considerados nas formas individual ou coletiva, previamente estruturados ou não.

Saba (2001) sistematiza a adesão do indivíduo à prática de atividade física em quatro momentos.

\begin{abstract}
$\mathrm{O}$ momento em que a pessoa não pratica exercício e nem pretende praticar; a fase em que o indivíduo se prepara para a prática, mas ainda não a executa; quando o indivíduo inicia a prática de exercício de forma esporádica, porém ainda não conhece todos os benefícios gerados por ele e finalmente a fase em que a pessoa cria consciência dos benefícios da prática regular do exercício, além de ter prazer, satisfação e o mesmo já fazer parte de sua rotina (SABA, 2001, p. 14).
\end{abstract}

Buscando compreender os fatores motivacionais, informados por Saba (2001) e que levam a adesão e aderência à prática da modalidade de Zumba Fitness em academias da cidade na sede do município de Petrolina/PE, além de identificar o perfil dos praticantes de Zumba, a influência da modalidade na motivação e a influência da academia na motivação dos praticantes, realiza-se este trabalho.

A prática do exercício físico em locais abertos e públicos é comum entre a população petrolinense, pois existem em vários bairros da cidade as "Academias da cidade" composta por vários 
Id on Line Revista Multidisciplinar e de Psicologia

Id on Line Multidisciplinary Journal and Psycology

aparelhos para a prática do exercício físico, além de aulas de Zumba em quadras esportivas nos bairros, que atendem principalmente as mulheres de várias idades.

\section{Metodologia}

O estudo foi realizado pelo método descritivo através de uma revisão de literatura, uma pesquisa exploratória de conteúdos relacionados à prática do exercício físico para buscar um bem estar e coleta de dados através de questionário aplicado em três praças da cidade em que existe a prática da Zumba, construído pelo pesquisador com perguntas fechadas. De posse dos resultados da entrevista os dados foram tabulados por meio de tabelas do programa Microsoft Office Word 2007, calculados em percentuais de respostas para as questões constadas na entrevista, e posteriormente a construção de tabelas, descrição e análise dos dados em relação aos objetivos do trabalho.

O trabalho foi referenciado através de pesquisas exploratórias e descritivas, por meio de endereços eletrônicos, revistas e artigos científicos, livros, conteúdos jornalísticos e publicações de órgãos oficiais e pesquisa monográfica do curso de bacharelado em Educação Física.

\section{Resultados}

Hass \& Garcia (2006) demonstram que o crescimento pela busca de práticas de atividade física para melhorar a qualidade de vida e incluem a dança como a opção que as pessoas buscam para mudar seu estilo de vida, por ser uma atividade prazerosa de se praticar. "A dança como atividade física melhora a disposição para as atividades do dia-a-dia podendo proporcionar ao indivíduo que a pratica, força muscular, estética corporal e autoestima, através dos movimentos realizados pela atividade" (HASS \& GARCIA, 2006, p. 38).

A dança torna-se uma atividade física alegre e que traz sensações de bem-estar, dando estímulos para que a pessoa a pratique sempre. Essa prática de atividade leva o indivíduo a ter mais motivação, autoestima e autodeterminação. Desse modo pode-se nos sentir mais tranquilos e mais felizes conosco e com outras pessoas ao nosso redor (SZUSTER, 2011). A autora ainda afirma que como qualquer outra atividade física, a dança pode beneficiar o indivíduo e retardar alguns problemas que podem ser diminuídos com o passar dos anos.

Segundo Szuster (2011, p. 29) "a dança enquanto atividade física tem muitos benefícios, melhora elasticidade muscular, melhora movimentos articulares, diminui o risco de doenças cardiovasculares, problemas no aparelho locomotor e sedentarismo, reduzindo o índice de pressão". 
Id on Line Revista Multidisciplinar e de Psicologia

Id on Line Multidisciplinary Journal and Psycology

Como assegura a autora, a prática de atividade física como a dança, garante melhoria na saúde das pessoas.

Szuster (2011) ainda assegura que a dança é um tipo de atividade física que permite ao indivíduo melhorar sua função física, sua saúde e seu bem-estar. A prática de exercícios físicos não só favorece na parte estética do indivíduo, mas proporciona também aos praticantes o benefício do sentirse bem. E, é através da dança, que é uma atividade física bem divertida de ser praticada, que muitos podem viver e alcançar uma determinada idade com boa saúde e muita disposição.

Nas academias, a procura pela dança é muito grande. Um dos motivos é o fato de as pessoas estarem acima do peso normal e buscarem meios de alcançar resultados que promovam a autoestima, visando assim a uma boa aparência da sua imagem corporal. A disposição de quem pratica atividade física pode aumentar, facilitando a realização de tarefas diárias, sem dar espaço ao sedentarismo e até mesmo às doenças. "O exercício físico é recomendado para prevenir doenças cardiovasculares, câncer, diabetes, além de aumentar a expectativa de vida”. (GONÇALVES \& VILARTA, 2004, p. 30).

\footnotetext{
Um grupo com a faixa etária de 50 a $60,62,5 \%$ responderam que buscam primeiro com a pratica da dança manter a forma e condição física, em segundo, 37,5 responderam que buscam manter a forma física e ao mesmo tempo fazer novas amizades e, em terceiro, 75\% buscam fazer novas amizades (SZUSTER, 2011, p. $50)$.
}

Pode-se ressaltar que a busca pela dança como uma atividade física proporciona manter o corpo em forma, ter uma boa aparência e além de fazer novas amizades, e os resultados são satisfatórios para a saúde de cada praticante, ocasionando aos órgãos públicos a pressão para que se criem cada vez mais locais para tal prática.

Ao fim da coleta de dados, foram analisadas as questões separadamente por seus tópicos: Perfil das alunas, Influência da academia na motivação e a influência da modalidade na motivação, ocasionando a confecção de tabelas com os dados.

Tabela 1: Perfil da amostra no estado civil e na idade.

\begin{tabular}{ccrc}
\hline Estado Civil & $\%$ & \multicolumn{1}{c}{ Idade } & $\%$ \\
\hline Casada & 71 & Até 30 anos & 14,5 \\
Solteira & 24,6 & Entre 30 e 50 anos & 46,3 \\
Divorciada & 4,3 & Acima de 50 anos & 39,1 \\
Ou Outro & & & \\
\hline
\end{tabular}

Fonte: Alves (2016)

Verifica-se que a grande maioria das praticantes do exercício físico em academia ao ar livre nas quadras poliesportivas dos bairros onde aconteceu a pesquisa de campo, são casadas e que por 
Id on Line Revista Multidisciplinar e de Psicologia

Id on Line Multidisciplinary Journal and Psycology

inúmeros motivos preferem está praticando as aulas de zumba, assim como verifica um considerável número de mulheres acima dos 30 anos praticando essa modalidade de exercício físico.

Tabela 2: Escolaridade.

\begin{tabular}{cc}
\hline Nível & $\%$ \\
\hline Fundamental & 5,6 \\
Fundamental incompleto & 4,2 \\
Médio & 27,8 \\
Médio incompleto & 23,6 \\
Superior & 16,7 \\
Superior incompleto & 4,2 \\
Outros & 9,7 \\
\hline
\end{tabular}

Fonte: Alves (2016)

Quanto ao nível de escolaridade, as participantes em sua maioria possuem o ensino médio, demonstrando que a busca por um bem-estar ocasiona opiniões favoráveis ao crescimento das academias ao ar livre, pois estas podem praticar a Zumba e não perder as horas para o estudo. Rojas (2003) numa pesquisa realizada na cidade de Curitiba - PR, com participação de 80 pessoas de ambos os sexos, constatou que as pessoas com ensino superior, completo ou incompleto, apresentaram maior aderência, 39,1\%, do que aquelas que estudaram até o ensino médio, 20,0\%, contrariando aos números desta pesquisa, onde a escolaridade superior está abaixo do ensino Médio.

Tabela 3: Procura por academia.

\begin{tabular}{cc}
\hline Principal motivo para praticar Zumba & $\%$ \\
\hline Saúde & 59,4 \\
Estética & 29 \\
Lazer & 5,8 \\
Outros & 5,8 \\
\hline
\end{tabular}

Fonte: Alves (2016)

Pedro (2013) em sua pesquisa feito no município de Criciúma - SC com alunos de treinamento funcional de ambos os sexos, obteve um total de $87 \%$ como principal motivo de adesão à prática de atividade física é em razão da saúde. Fato que motiva, ainda mais, a criação de locais que possam ser utilizados para a prática de exercícios físicos, incluso a Zumba.

Tabela 4: Academia das cidades.

$\begin{array}{cc}\text { Motivo de participação da aula de zumba } & \% \\ \text { Qualidade dos professores } & 11,6 \\ \text { Indicação de amigo } & 14,5\end{array}$


Id on Line Revista Multidisciplinar e de Psicologia

Id on Line Multidisciplinary Journal and Psycology

\begin{tabular}{cc}
\hline Proximidade & 40,6 \\
Ambiente agradável & 8,7 \\
Horário & 23,1 \\
Outros & 1,4 \\
\hline
\end{tabular}

Fonte: Alves (2016)

Forgiarini (2012) realizou no município de Criciúma um estudo onde foi relatada qual a forma de divulgação que levou a procurar por uma academia, mesmo sendo a academia particular, $57 \%$ dos entrevistados de ambos os sexos responderam a indicação de amigos.

$\mathrm{Na}$ cidade a procura pelas academias é grande e nem todos tem condições financeiras de custear as aulas de dança, a população dos bairros atendidos pelo programa da "Academia das cidades" que utilizam a zumba como exercício físico procuram participar ativamente das atividades da zumba e, como demonstrado na tabela 4, a grande maioria das entrevistadas aproveitam o horário e a proximidade com sua residência para poderem praticar uma atividade física e consequentemente obter um bem-estar e boa saúde.

Tabela 5: Adesão a zumba.

\begin{tabular}{cc}
\hline Vantagens encontradas na aula de zumba & $\%$ \\
\hline Bem-estar pós aula & 26,1 \\
Instrutor contagiante & 26,1 \\
Aula agradável, companhias & 17,4 \\
Trabalha o corpo (saúde, força e elegância) & 15,9 \\
Queima de calorias (stress) & 14,5 \\
\hline
\end{tabular}

Fonte: Alves (2016)

Mendes (1988) cita que a dança junto com a música faz parte de nosso dia a dia: das festas de aniversário ao carnaval, são muitas as ocasiões e os pretextos para a dança no convívio social: em roda, aos pares e em grupo. Sobre as vantagens encontradas nas aulas, verificou-se que a sensação de bem estar pós-aula foi o motivo principal escolhido, com $26,1 \%$, seguido por instrutor contagiar positivamente o grupo com $26,1 \%$, a turma companheira e unida $17,4 \%$, trabalho corporal que a aula proporciona $15,9 \%$ e queima calórica que a aula proporciona $14,5 \%$. Percebendo que em segundo lugar, na tabela 3, um dos maiores fatores motivacionais encontrados para aderência da academia foi a estética, nesta tabela, especificamente sobre as aulas de zumba, o fator mais evidenciado foi a sensação de bem estar pós aula, o que mostra que a questão psicológica tem grande influência na permanência das alunas nas aulas de zumba.

Para Saba (2001) o segundo elemento de influência relevante na aderência à pratica de exercício é a sensação de satisfação originada pelos ganhos no bem-estar físico e psicológico.

Tabela 6: Tempo de prática da zumba. 
Id on Line Revista Multidisciplinar e de Psicologia

Id on Line Multidisciplinary Journal and Psycology

\begin{tabular}{cc}
\hline Tempo & $\%$ \\
\hline Até 3 meses & 29 \\
De 3 a 6 meses & 14,5 \\
De 6 a 11 meses & 13 \\
Acima de 1 ano & 43,5 \\
\hline
\end{tabular}

Fonte: Alves (2016)

Sobre o tempo de prática na academia, são citados 3 meses com 29\%, 6 meses com 14,5\%, 11 meses com $13 \%$ e 1 ano ou mais com 43,5\%. É bem percebido o grande percentual de pessoas que ainda estão aderindo à prática e os que já estão fidelizados na academia, ficando os 6 e 11 meses com baixo percentual. Oliveira (2011, p. 43) em sua pesquisa relatou que " $30,88 \%$ mulheres praticam exercícios nas academias por um período menor que 3 meses. Já os homens pareceram mais fiéis aos programas, onde entre estes 19,79\% frequentam academias por no mínimo 1 a 2 anos", contrariando o resultado de Oliveira, aqui consta que as mulheres têm se fidelizado cada vez mais a programas de atividades físicas.

Com relação às fases em que Saba (2001) cita percebesse que as pessoas que estão nos 3 meses apresentam-se na fase ação onde a pratica de exercício ainda é esporádica, eles ainda não compreendem todos os benefícios da atividade física. Já os que estão a 1 ano ou mais apresentam-se na fase de manutenção e aderência, onde já estão conscientes dos benefícios, tem prazer, satisfação da pratica e já faz parte da rotina.

Tabela 7: Atração na aula de zumba

\begin{tabular}{ccccc}
\hline & Professor & Musica & Coreografia & Ambiente \\
\hline $1^{\mathbf{0}}$ lugar & $37,7 \%$ & $34,8 \%$ & $27,5 \%$ & $0 \%$ \\
$2^{\mathbf{o}}$ lugar & $29 \%$ & $44,9 \%$ & $23,2 \%$ & $2,9 \%$ \\
$3^{\mathbf{0}}$ lugar & $31,9 \%$ & $21,7 \%$ & $43,5 \%$ & $2,9 \%$ \\
$4^{\mathbf{0}}$ lugar & $1,4 \%$ & $1,4 \%$ & $1,4 \%$ & $95,7 \%$ \\
\hline
\end{tabular}

Fonte: Alves (2016)

A tabela 7 mostra que a atração maior na aula de zumba é o professor seguido pela música, coreografia e o ambiente ficando em último lugar.

Pedro (2013) ao pesquisar se a influência do professor na adesão do treinamento funcional constatou que $61 \%$ dos entrevistados apontaram que sim. Assemelhando-se com a importância do professor citado na modalidade de zumba.

Mendes (1988) cita que a música é parte integrante e essencial na estrutura dessas aulas. A ligação entre a música e atividades motoras tem sido reconhecida tanto em indivíduos em reabilitação, quanto para praticantes de atividade física, cujo objetivo é a manutenção da saúde. 
Id on Line Revista Multidisciplinar e de Psicologia

Id on Line Multidisciplinary Journal and Psycology

\section{Discussões/Conclusões}

De acordo com a pesquisa apresentada pode-se concluir que a dança é uma atividade física que proporciona benefícios em prol da saúde, mas o que mais teve relevância foi a perda de peso e melhoria da autoestima e a proporção do bem-estar pós aula, ocasionando uma saúde mais perfeita nos praticantes da zumba.

A dança se caracteriza como uma fonte que oferece bem-estar e um bom condicionamento físico, integração social, e é uma atividade física que além do prazer de se praticar, favorece vários outros benefícios para uma boa qualidade de vida. Além desses benefícios ressaltados pelas alunas foi acrescentado também, na pesquisa, que a dança é uma terapia motivacional.

A prática da zumba ocasionando um grande benefício para a saúde da população praticante faz-se, então, necessário que o gestor público proporcione a maior quantidade possível de pessoas uma prática de tal atividade física, o que proporcionará uma melhor qualidade de vida com saúde, beneficiando, assim, não somente a saúde da comunidade mais também trará benefícios educacional e econômico, benefício financeira, estes, para o próprio município, pois com a população esbanjando saúde o mesmo economizará seus recursos na área da saúde ocasionando a sobra de mais recursos para investir em outros setores que beneficiará a própria comunidade, ou reconduzindo os recursos para implantação de outras “Academias das cidades”, aumentando o número de participantes.

\section{Referências}

ARSEGO, N. R. Motivação a pratica regular de atividades físicas na academia de ginástica: uma revisão de literatura, monografia apresentada na escola de Educação Física da Universidade federal do Rio Grande do Sul. 2012.

BARBANTI, V. J. Dicionário de educação física e do esporte. São Paulo: Manole, 1994.

FERREIRA, A. B. H. Minidicionário da língua portuguesa. Rio de Janeiro: Nova Fronteira, 16 1993.

FORGIARINI, L. Adesão de clientes na academia após aplicação de estratégia de marketing: Um estudo de caso. 2012. 52 f. TCC (Curso de Educação Física) - Universidade do Estremo Sul Catarinense, Criciúma, 2012.

GONÇALVES, A.; VILARTA, R. Qualidade de vida e Atividade física. Explorando teoria e pratica. Barueri, SP: Manole, 2004.

HASS, A. N.; GARCIA, A. Ritmo e dança. Canoas. Ed. ULBRA, 2006. 
Id on Line Revista Multidisciplinar e de Psicologia

Id on Line Multidisciplinary Journal and Psycology

MENDES, M. V. A dança. São Paulo: E. Claro, 1988.

OLIVEIRA, J. J. Motivos de adesão aos programas de exercícios físicos: um estudo exploratório com praticantes de academias de musculação e ginástica na cidade de Criciúma - SC. 2011. 52 f. TCC (Curso de Educação Física) - Universidade do Extremo Sul Catarinense, Criciúma, 2011.

PEDRO, D. L. Motivos de adesão e aderência ao treinamento funcional orientado no município de criciúma - SC. 2013, 32f. TCC (Curso de Educação Física) - Universidade do Extremo Sul Catarinense, Criciúma, 2013.

ROJAS, C. N. P. Aderência aos programas de exercícios físicos em academias de programas de ginástica na cidade de Curitiba - PR. 2003, 127f. Dissertação (Mestre em Educação Física). Área de Concentração: Atividade Física Relacionada à Saúde. Universidade Federal de Santa Catarina, Florianópolis, 2003.

SABA, F. Aderência à prática do exercício físico em academias. São Paulo: Manole, 2001.

SZUSTER. Estudo qualitativo sobre a dança como atividade física em mulheres acima 50 anos. $69 \mathrm{f}$. (Monografia de Bacharel em Educação Física) Porto Alegre - RS: 2011.

Como citar este artigo (Formato ABNT):

ALVES, J.N.; NASCIMENTO, D.C. Dança de Zumba como Instrumento em prol da Saúde e do Bem estar para comunidades periféricas do Município. Id on Line Revista Multidisciplinar e de Psicologia, Julho de 2016, vol.10, n.30, Supl 3, p. 07-15. ISSN 1981-1179.

Recebido: 30/06/2016

Aceito: 11/07/2016 